\title{
Description of the oviparous female and new information on the biology of the rare aphid Stomaphis radicicola Hille Ris Lambers 1947 (Hemiptera, Aphidoidea)
}

\author{
Lukasz Depa, Ewa Mróz \& Jolanta Brożek
}

\begin{abstract}
Depa, Ł., Mróz, E. \& Brożek, J. 2013: Description of the oviparous female and new information on the biology of the rare aphid Stomaphis radicicola Hille Ris Lambers 1947 (Hemiptera, Aphidoidea). — Entomol. Fennica 24: 100-106.

Information is provided concerning the discovery of the rare aphid species Stomaphis radicicola $\mathrm{H}$. R. Lambers in Slovakia. The first description of the oviparous morph is given and its morphological resemblance to $S$. bratislavensis Czylok et Blackman is discussed. Supplementary data concerning the molecular identity and biology of $S$. radicicola is presented.
\end{abstract}

Ł. Depa, E. Mróz \& J. Brożek, Department of Zoology, Faculty of Biology and Environmental Protection, University of Silesia, Bankowa 9, PL 40-007 Katowice; Correspondent author's e-mail: lukasz.depa@us.edu.pl

Received 1 June 2012, accepted 20 September 2012

\section{Introduction}

The aphid genus Stomaphis (Walker) (Aphidoidea, Lachnidae) comprises about 30 species, remarkable for their large body size and very long rostrum. Such a long rostrum, much longer than the body, enables them to probe through the bark of trees, mainly deciduous, on which they feed. On the other hand, it strongly disables their escape in case of any danger. Consequently, to deter natural enemies, all the species of this genus strongly depend upon their mutualistic relations with ants, mostly from the genus Lasius. It may also be a reason why these aphids feed in bark crevices or under bark in ant chambers, which also makes them very difficult to be found by researchers (Depa 2012, Depa et al. 2012). Given their discrete feeding positions, it is not surprising that Stomaphis aphids are considered rare. At least 5 European species of this genus are known only from single sites: $S$. acquerinoi Binazzi, $S$. juglandis Petrović, S. knechteli Binazzi et Black- man, $S$. radicicola $H$. R. Lambers and $S$. bratislavensis Czylok et Blackman. The latter species was found in Šur Natural Reserve (Slovakia), which is the type locality. There is no other record of its presence in Europe. The species described by Czylok and Blackman (1991) feeds on trunks of Quercus petrea Liebl., and in its appearance in life strongly resembles $S$. radicicola. The latter was described in 1947 by Hille Ris Lambers based on specimens collected in Leersum, Netherlands (Hille Ris Lambers 1947) (Fig. 1). The only known aspect of its biology is that it was feeding underground on the roots of Betula sp. and was attended by the ant Lasius umbratus (Nylander). Since its description there have been no records or observations of the biology of $S$. radicicola in Europe (Blackman \& Eastop 1994, www.aphidsonworldsplants.info).

Since a few species of the genus Stomaphis are known only from single sites, in 2011 extensive field research was undertaken in Poland, Czech Republic, Slovakia, Hungary, Austria and 
Slovenia, to form the basis of molecular and phylogeographic studies. Despite detailed searching in its type locality, no colony of $S$. bratislavensis was found. Instead, a single adult female and larvae of $S$. radicicola were discovered, i.e. the first record of this species since its description. Despite further searching within the locality, no other colonies were found.

Here we present data on the rediscovery of this rare aphid species in the Šur Natural Reserve, with the description of the collected specimen and details on its biology and taxonomical position within the genus, based on a molecular analysis with mitochondrial marker COXI. This marker was chosen, because it is effective in resolving problems with species identity of aphids, the detection of morphologically cryptic species and the detection of host-specific lineages (Foottit et al. 2008, 2009, Wang \& Qiao 2009, Kim et al. 2011, Depa et al. 2012).

\section{Material and methods}

The collection site was situated in the Šur Natural Reserve, which received its status in 1952 and became a significant refuge for some most interesting forms of wildlife at the foot of Malé Karpaty Mountains. The reserve is situated $12 \mathrm{~km}$ north of Bratislava and $5 \mathrm{~km}$ away from the small town of Svaty Jur. The Reserve comprises two main plant communities, distinct for their rarity and species diversity: the alder swamp forest (Jelšovy les) of Alnion glutinosae plant association and the xerothermic oak wood (Panónsky háj) of (Quercion petreae) plant association referred to as the Pannonian wood. These two plant communities have already been subject to aphidological research which revealed the presence of 88 aphid species (Czylok et al. 1991).

An oviparous female and two larvae of $S$. $\mathrm{ra}$ dicicola were collected on 2.X.2011 in Šur Natural Reserve (Slovakia) (Fig. 1), in an alder forest (48 $\left.{ }^{\circ} 13^{\prime} 54^{\prime \prime} \mathrm{N}, 17^{\circ} 12^{\prime} 33^{\prime \prime} \mathrm{E}\right)$. The aphids were feeding on Alnus glutinosa (L.) Gaertn., about 1.5 $\mathrm{m}$ above ground level, in a deep crevice of bark, partly under it. They were attended by ant workers of Myrmica rubra (Linnaeus). The aphids were whitish and slightly wax dusted.

For a morphological comparison with $S$.

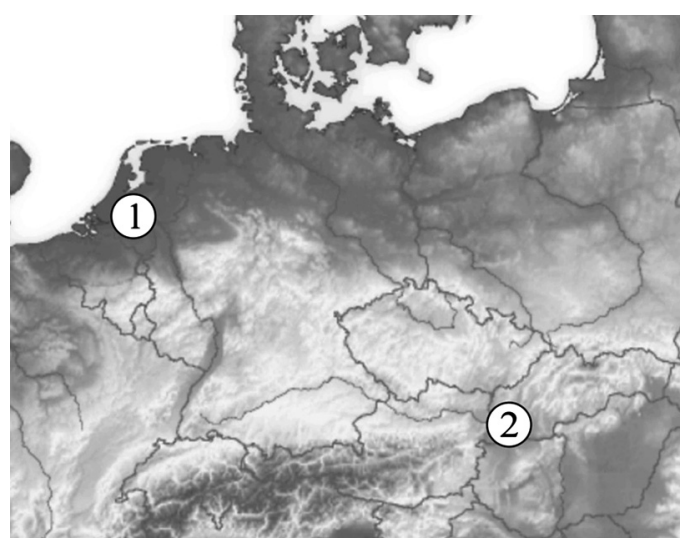

Fig. 1. Known localities of Stomaphis radicicola in the Netherlands (1) and Slovakia (2).

radicicola, the type material (holotype and 5 paratypes) of $S$. bratislavensis were examined. These and the microscope slide of the collected $S$. radicicola adult oviparous female are deposited in the collection of the Zoology Department of the University of Silesia.

Molecular analysis of the collected $S$. radicicola material was conducted to compare its barcode sequence COXI with sequences of other representatives of the genus available in GenBank. The sequences of the following species of Stomaphis were used: S. quercus (Linnaeus) (2 samples from different host plants: Betula and Quercus), S. wojciechowskii Depa, S. graffii Cholodkovsky and $S$. longirostris (Fabricius). Only single sequences of these species were applied, because the barcode sequence within the species of this genus is very constant and sequences of particular species differ only by single nucleotides (Depa et al. 2012). One sequence of $S$. radicicola was applied because of the lack of specimens. The voucher specimens are kept in $80 \%$ ethanol and deposited in Department of Zoology, University of Silesia. The individuals of each species used for the molecular analysis were taken from the same colonies as voucher specimens and were probably members of the same clones (Depa et al. 2012).

Two species belonging to the family Lachnidae, Trama rara Mordvilko and Tuberolachnus salignus (Gmelin), were chosen as the out-group. Trama rara was chosen in the outgroup, because the tribe Tramini is regarded by some authors as a sister group for Stomaphidini 
Table 1. GenBank accession numbers for sequences of specimens used in this study. For $S$. quercus, B: collected on Betula, Q: collected on Quercus.

\begin{tabular}{ll}
\hline Species & Accession no. \\
\hline Trama rara & EU701939 \\
Tuberolachnus salignus & EU701942 \\
Stomaphis graffii & JQ302805 \\
S. longirostris & JX137025 \\
S. wojciechowskii & JQ30280 \\
S. quercus (B) & JN944547 \\
S. quercus (Q) & JN944548 \\
S. radicicola & JX863574 \\
\hline
\end{tabular}

(Czylok 1990). The second out-group species, T. salignus feeds on Salicaceae, as do some species of the genus Stomaphis. Their sequences used in the molecular analysis were obtained from GenBank. The complete list of the taxa and the accession numbers of the sequences are presented in Table 1.

The sample of $S$. radicicola for molecular analysis was kept in 95\% - 100\% ethanol and stored at $4{ }^{\circ} \mathrm{C}$. Total genomic DNA was isolated using DNeasy Tissue Kit (Qiagen) following the manufacturer's instructions. The mitochondrial gene COXI was studied. The primers used for the PCR amplifications were LCO 1490 and HCO 2198 (Folmer et al. 1994). The mitochondrial gene fragment was amplified as follows: initial denaturation at $94^{\circ} \mathrm{C}$ for $1 \mathrm{~min}$, followed by 35 cycles of $94^{\circ} \mathrm{C}$ for $30 \mathrm{~s}$; annealing temperatures 47 for $45 \mathrm{~s}$; extension at $72^{\circ} \mathrm{C}$ for $1 \mathrm{~min}$; final extension at $72^{\circ} \mathrm{C}$ for $3 \mathrm{~min}$. PCR products were purified using a QIAquick ${ }^{\circledR}$ PCR purification Kit (QIAGEN) and sequenced directly using an automated sequencer (Genome Sequencer GS FLX Roche). The studied sequence of $S$. radicicola was deposited in GenBank under accession number given in Table 1, where it is presented together with the accession numbers of the sequences of other species used for the phylogenetic analysis. The voucher specimens are deposited in the collection of the Department of Zoology, University of Silesia.

Chromatograms, including sense and antisense, were analysed using Chromas V2.3 (Technelysium Pty Ltd. 2004) software. Alignments for the studied sequence were made using Clustal X (Thompson et al. 1997).
Tree reconstructions based on nucleotide sequences were carried out by maximum-likelihood (ML) method, neighbour-joining (NJ) (Saitou \& Nei 1987) and maximum parsimony (MP) (Swofford et al. 1996) as implemented in MEGA version 5 (Tamura et al. 2011). The ML tree was obtained using the general time reversible model with a proportion of invariant sites (GTR +I - General Time Reversible + Invariant Sites) (Tamura \& Nei 1993), because it scored the lowest BIC (Bayesian Information Criterion) value when different models of substitution pattern were tested. The bootstrap consensus tree inferred from 1,000 replicates was taken to represent the evolutionary history of the taxa analyzed (Felsenstein 1985). Branches corresponding to partitions reproduced in less than $50 \%$ bootstrap replicates were collapsed.

\section{Results}

\subsection{Description of the collected Stomaphis radicicola specimen (Fig. 2)}

Body: Oval, $5.92 \mathrm{~mm}$ long and $2.9 \mathrm{~mm}$ wide at maximum, covered with very dense and short pubescence.

Head: Sclerotised, medium pigmented; antennae $2.11 \mathrm{~mm}$ long (length of particular seg-

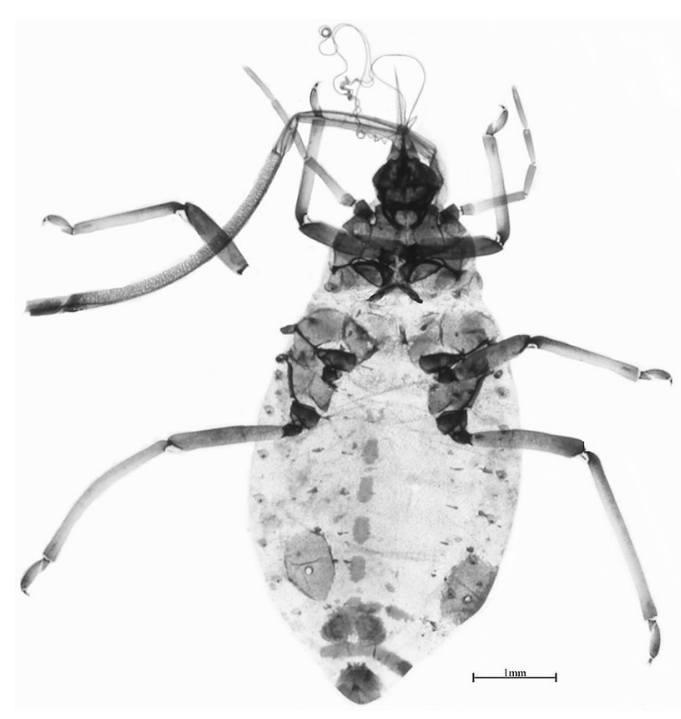

Fig. 2. Oviparous female of $S$. radicicola. 


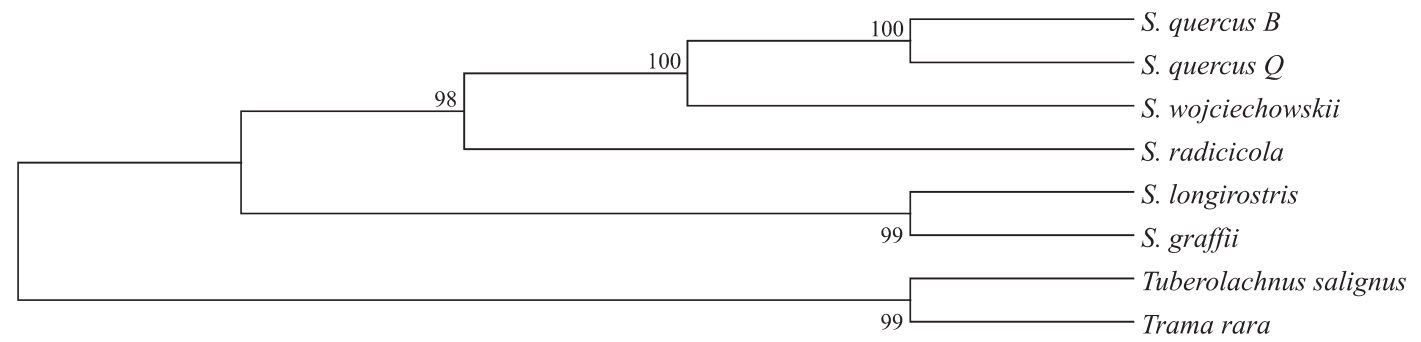

Fig. 3. Results of Maximum Likelihood of COXI sequences. Bootstrap values are indicated on the branches when higher than 50. B: S. quercus collected on Betula, Q: S. quercus collected on Quercus.

ments: I-0.21, II-0.14, III-0.56, IV-0.33, V0.38 , VI- -0.49 ), constituting 0.36 of body length; antennal segment VI 1.29 times the length of antennal segment V; III antennal segments with 1 rhinarium both, IV antennal segments with 3 and 5 small rhinaria, antennal segments $\mathrm{V}$ and VI only with single, large and oval primary rhinaria. Processus terminalis rounded, $0.07 \mathrm{~mm}$ long, 0.18 of the basal part of antennal segment VI, covered with many hairs of the same length as the rest of the segment. Labrum covered with many short hairs. Rostrum long, telescopic, covered with many short hairs (ultimate segments of rostrum missing in the microscope slide).

Thorax: Weakly pigmented, pronotum and mesonotum with small and weakly pigmented, paired spinal sclerites, matanotum only with a paired group of a few small scleroits; coxae and trochanters dark, darker than femora, tibiae pale with darker bases and distal apices. Hairs on legs, antennae and rostrum slightly shorter than on other parts of the body. Hind femora 1.26-1.31 and hind tibiae 1.82-1.92 mm long. Length ( $\mathrm{mm}$ ) of I segment of middle tarsus 0.13, II segment of middle tarsus 0.29 . Length of I segment of hind tarsus 0.13 , II segment of hind tarsus 0.38 . Ratio of II segment of middle tarsus to II segment of hind tarsus 1.31.

Abdomen: Membranous, provided with dark intersegmental muscle insertions; Abdominal sternites III-VII with five glabrous, distinctly sclerotized patches, arranged medially of which last one is partially fused with subgenital plate; sclerotic patch also on the sternite II, but weakly pigmented and broken in the middle. Subgenital plate not divided, however with distinct median groove of weak sclerotisation. No traces of spinal scleroits except for the weakly pigmented cross bar on the VII tergite, broken medially, and a ring of sclerotisation on the VIII segment. Siphunculus surrounded by large, pigmented cone 0.79 $\mathrm{mm}$ long and $0.53 \mathrm{~mm}$ wide, the aperture 0.07 $\mathrm{mm}$ in diameter. Cauda short, rounded, with numerous hairs, not longer than on other parts of abdomen.

\subsection{Molecular analysis}

The alignment of partial COXI sequences contained 635bp sites, and the nucleotide frequencies were $\mathrm{A}=34.33 \%, \mathrm{~T} / \mathrm{U}=41.28 \%, \mathrm{C}=14.21 \%$, and $\mathrm{G}=10.18 \%$. The estimated transition/transversion bias (R) was 1.80 and there were $68.36 \%$ of evolutionarily invariable sites.

The tree reconstructions based on nucleotide sequences carried out by the maximum-likelihood (ML) method proved the species identity of $S$. radicicola and its separateness from the other studied species of the genus (Fig. 3). It constituted a clade with $S$. quercus and $S$. wojciechowskii, which was the sister clade to $S$. graffii and $S$. longirostris. In agreement with ML and other methods (NJ, MP - not shown), the sister relationship of $S$. radicicola and the clade consisting of $S$. quercus and $S$. wojciechowskii was supported by higher bootstrap values, over $90 \%$.

\section{Discussion}

The Šur Natural Reserve is a very interesting area for further faunistic research. The occurrence of at least two very rare aphid species supports its status of a protected area. It may also indicate, through the maintenance of rare habitat types typical for the region of the Pannonian Basin, that the species diversity of this region is still far from well known. 


\subsection{Taxonomic comments on the morphological and molecular results}

The morphological features of the specimen collected in Sur match well to the range of variability of the specimens described by Hille Ris Lambers. Despite the fact, that only a single specimen was studied, it cannot be mistaken neither for the fundatrix (as that occurs in early spring) nor with the alate morph (lack of wings). Furthermore, the notable differences with apterous viviparous females described by Hille Ris Lambers were recorded: shorter antennae, different ratios of length of antennal segments and also the brighter groove through the genital plate. The lack of more individuals does not allow the study of morphological variability within this morph of the species.

Although the collected specimen was an oviparous female, both diagnostic features (ratios of last two antennal segments (Fig. 4a,b) and second segment of hind tarsus (Fig. 4c,d) to middle tarsus) (Czylok \& Blackman 1991) allow the distinction of this species from both the viviparous and oviparous female of $S$. bratislavensis. These two species differ also in other morphological characters.

According to the original description of $S$. bratislavensis there are five ventral patches on the abdomen. Yet in fact there are six ventral patches, with the last one merged with the subgenital plate, and thus it is less visible and can be mistaken as a sclerotisation of the subgenital plate. This sixth patch can be recognised by its microsculpture, which is more rugose and punctuated than that of the subgenital plate. In $S$. radicicola the situation is similar, but the first abdominal ventral patch is less sclerotised and broken in the middle. The shape of these patches is also different in these species (Fig. 4e,f). In $S$. bratislavensis they are distinctly longer than wide (length/width ratio is $1.93 \pm 0.12$ ) with irregular edges, while in $S$. radicicola they are more oval or even rectangular (length/width ratio $1.58 \pm 0.11$ ) with more uniform edges.

Generally, among other European representatives of the genus, the number and shape of these ventral sclerotisations of $S$. radicicola resemble those of $S$. quercus and the newly described species $S$. wojciechowskii (Depa et al. 2012). The relative similarity of these species was confirmed by the molecular analysis (Fig. 3).

Our cladogram based on the COXI sequences (Fig. 3) also shows that $S$. radicicola is placed between the well sclerotised $S$. quercus and the weakly sclerotised $S$. graffii, which agrees with the morphology-based taxonomy. Accordingly, the number, shape and degree of the sclerotisations of the ventral plates are good candidates for indicators of the phylogenetic relations within the genus. Further analysis, supplemented with other barcode sequences and other rare representatives of the genus (e.g. S. bratislavensis) are expected to clarify the importance of these and other morphological features, such as ratios of antennal segments or tarsal segments (Binazzi \& Blackman 2003, Depa et al. 2012), in phylogenetic relations among Stomaphis species.

\subsection{Comments on the ecology of $S$. radicicola}

The current study brought also new information about the biology of $S$. radicicola. Most species of Stomaphis are considered monophagous, but $S$. radicicola was discovered feeding on a different plant genus to the one it was described from. Both its host plants, Betula and Alnus, are closely related genera belonging to the family Betulaceae (Chen et al. 1999) and are typical for the biome of broadleaf forests of the temperate zone of the Northern Hemisphere. So, this species should be regarded as oligophagous, with representatives of the family Betulaceae as its host plants, until any further host plant associations are recorded.

Myrmica rubra (Myrmicinae) has not been recorded previously attending species in the genus Stomaphis. Myrmica rubra is a eurytopic ant, particularly abundant in lowlands where it inhabits various habitats, including forests (Collingwood 1979, Czechowski et al. 2002). In forests, it is one of the dominant ant species involved in mutualistic relations with aphids (Depa \& Wojciechowski 2009). Furthermore, the feeding location of $S$. radicicola requires the presence of ants to deter natural enemies. The original description gives information about the attendance by $L$. umbratus, which is an ant species with very cryptic, subterranean way of life, occurring only rarely above ground (Collingwood 1979). It 

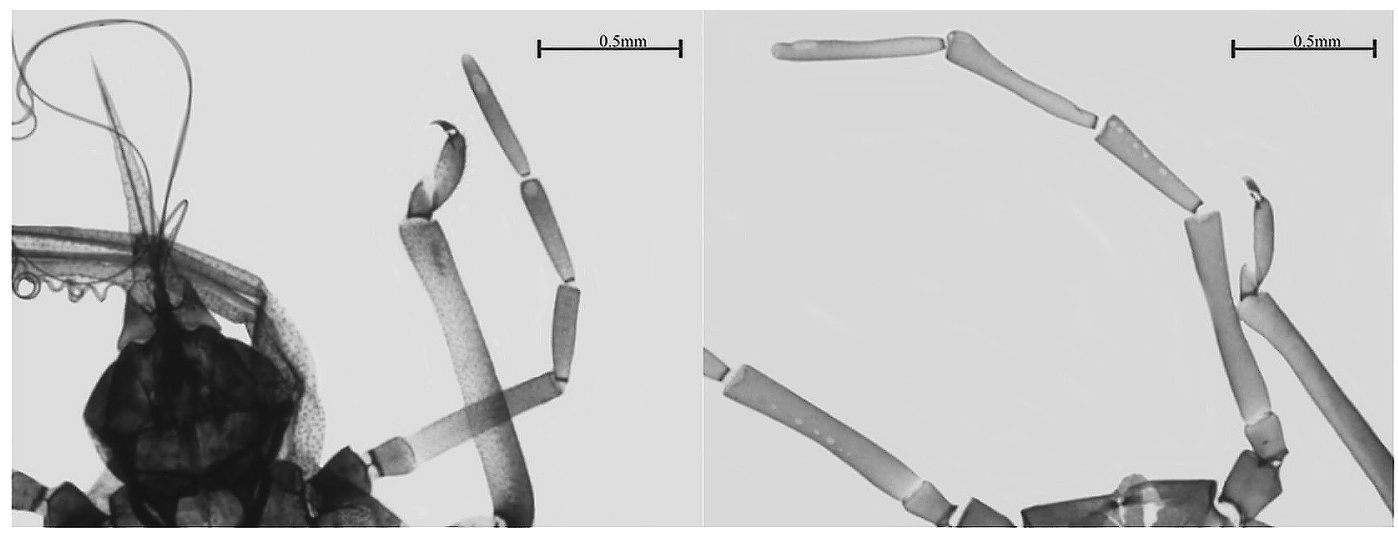

a

b

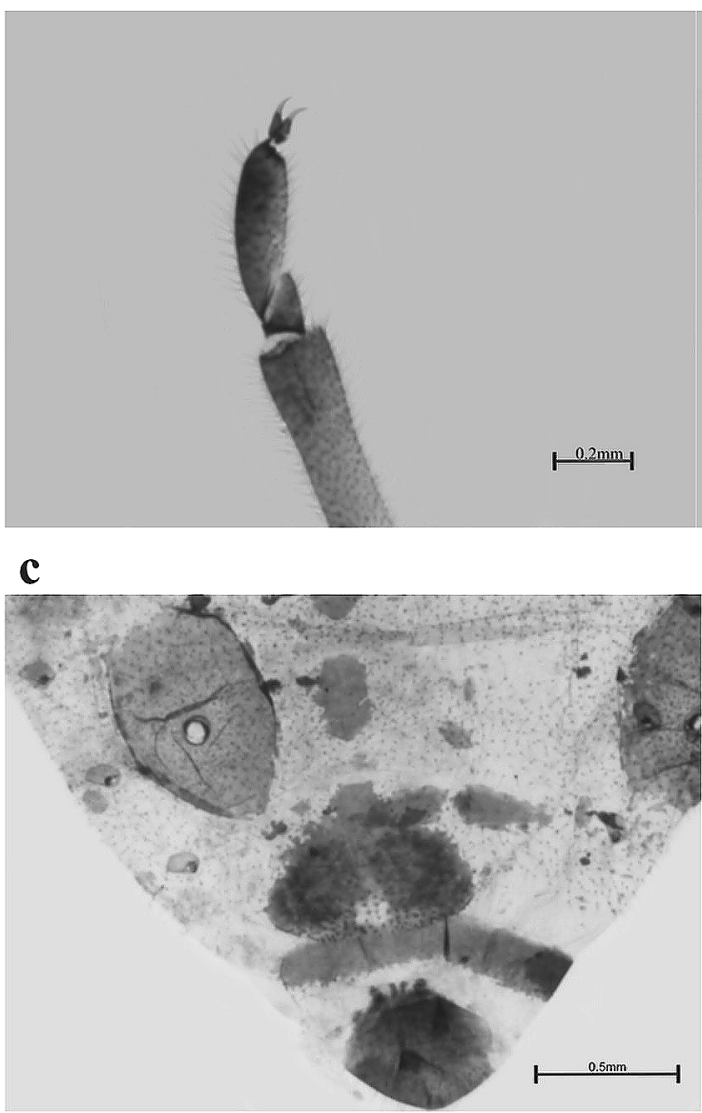

\section{e}

f

Fig. 4. Morphological differences between S. radicicola (a, c, e) and S. bratislavensis (holotype) (b, d, f). - a, b. Antennal segments. - c, d. Hind tarsus. - e, f. Subgenital plate, siphunculi and ventral patches.

builds nests deep in the ground among roots of trees, where it probably tends root-feeding aphids such as $S$. radicicola. In contrast, $M$. rubra is an above ground forager that climbs plant stems or trunks in search of food, including colonies of aphids. Thus, the feeding location of $S$. radicicola on the trunk, when attended by M. rubra, may not be unusual. 
Acknowledgements. We would like to thank prof. Il'ja Krno and prof. Jozef Halgoš (Department of Ecology, Comenius University in Bratislava) for making our stay in Biologická stanica Súr possible. We also thank two anonymous referees for constructive criticism which helped to improve the manuscript. We are also indebted to Ed Baker for linguistic amendment of the manuscript.

\section{References}

Binazzi, A. \& Blackman, R. 2003: The Acer-feeding Stomaphis with description of a new species and new morphs (Hemiptera Aphididae Lachninae). — Redia 86: 7-16.

Blackman, R. L. \& Eastop, V. F. 1994: Aphids on the World's Trees. - CAB International, Wallingford, $987 \mathrm{pp}+16$ plates.

Chen, Z. D., Manchester, S. R. \& Sun, H. Y. 1999: Phylogeny and evolution of the Betulaceae as inferred from DNA sequences, morphology, and paleobotany. American Journal of Botany 86: 1168-1181.

Collingwood, C. A. 1979: The Formicidae (Hymenoptera) of Fennoscandia and Denmark. - Fauna Entomologica Scandinavica 8, 174 pp.

Czechowski, W., Radchenko, A. \& Czechowska, W. 2002: The ants (Hymenoptera, Formicidae) of Poland. - Museum and Institute of Zoology PAS, Warsaw, 200 pp.

Czylok, A. 1990: Phylogenetic concept of Tramini (Homoptera, Lachnidae). - Prace Naukowe Uniwersytetu Śląskiego No. 1130: 1-64.

Czylok, A. \& Blackman, R. L. 1991: A new species of Stomaphis Walker (Homoptera: Aphididae) from Czechoslovakia. - Journal of Natural History 25: 665-669.

Czylok, A., Halgoš, J. \& Wojciechowski W. 1991: Aphids (Aphidinea) of the Šur Natural Reserve near Bratislava. - Acta Biologica Silesiana 18(35): 9-16.

Depa, Ł. \& Wojciechowski, W. 2009: Aphids (Hemiptera: Aphidinea) of Garb Tarnogórski and their trophobiotic relations with ants. - Annals of Upper Silesian Museum (Entomology) 18: 5-110.

Depa, Ł. 2012: Abundance of Stomaphis graffii Cholod. (Hemiptera) on maple trees in Poland. - Central European Journal of Biology 7(2): 284-287.

Depa, Ł., Mróz, E. \& Szawaryn, K. 2012: Molecular identity of Stomaphis quercus (L.) (Hemiptera, Aphidoidea) and description of a new species. - European Journal of Entomology 109(3): 435-444.
Felsenstein, J. 1985: Confidence limits on phylogenies: An approach using the bootstrap. - Evolution 39: 783 791.

Folmer, O., Black, M., Hoeh, W., Lutz, R. \& Vrijenhoek, R. 1994: DNA primers for amplification of mitochondrial cytochrome c oxidase subunit I from diverse metazoan invertebrates. - Molecular Marine Biology and Biotechnology 3: 294-299.

Foottit, R. G., Maw, H. E. L., von Dohlen, C. D. \& Hebert, P. D. N. 2008. Species identification of aphids (Insecta: Hemiptera: Aphididae) through DNA barcodes. Molecular Ecology Resources 9 (Suppl. 1): 188-195.

Foottit, R. G., Maw, H. E. L. \& Pike, K. S. 2009: DNA barcodes to explore diversity in aphids (Hemiptera Aphididae and Adelgidae). — Redia 92: 87-91.

Hille Ris Lambers, D. 1947: Some west European aphids. - Zoologische Mededelingen 28: 291-333.

Kim, H., Lee, S. \& Jang, Y. 2011: Macroevolutionary Patterns in the Aphidini Aphids (Hemiptera: Aphididae): Diversification, Host Association, and Biogeographic Origins. — PLoS ONE 6(9): e24749. doi:10.1371/ journal.pone.0024749

Tamura, K. \& Nei, M. 1993: Estimation of the number of nucleotide substitutions in the control region of mitochondrial DNA in humans and chimpanzees. - Molecular Biology and Evolution 10:512-526.

Tamura, K., Peterson, D., Peterson, N., Stecher, G., Nei, M. \& Kumar, S. 2011: MEGA5: Molecular Evolutionary Genetics Analysis using Maximum Likelihood, Evolutionary Distance, and Maximum Parsimony Methods. - Molecular Biology and Evolution 28(10): 2731-2739.

Technelysium Pty Ltd. 2004, "Chromas," http://www. technelysium.com.au/chromas.html.

Saitou, N. \& Nei, M. 1987: The neighbor-joining method: a new method for reconstructing phylogenetic trees. - Molecular Biology and Evolution 4: 406-425.

Swofford, D. L., Olsen, G. J., Waddell, P. J. \& Hillis, D. M. 1996: Phylogenetic inference. - In: Hillis, D. M., Moritz, C., Mable, B. K. (eds.), Molecular Systematics: 407-514. Sinauer Associates, Sunderland, MA.

Thompson, J. D., Gibson, T. J., Plewniak, F., Jeanmougin, F. \& Higgins D. G. 1997: The ClustalX windows interface: flexible strategies for multiple sequence alignment aided by quality analysis tools. - Nucleic Acids Research 24: 4876-4882.

Wang, J. \& Qiao, G. 2009: DNA barcoding of genus Toxoptera Koch (Hemiptera:Aphididae): Identification and molecular phylogeny inferred from mitochondrial COI sequences. - Insect Science 16: 475-484. 